\title{
Lower Urinary Tract Symptoms Among Females with Rheumatoid Arthritis: A Prospective Cross-Sectional Study
}

\author{
Faris Abushamma (iD 1,2 \\ Narjis Nassar (D) \\ Sulafa Omar Najjar (D) \\ Sobhe Mahmoud Hijaze (D) \\ Amer Koni ${ }^{3,4}$ \\ Sa'ed H Zyoud (iD ${ }^{4-6}$ \\ Amir Aghbar ${ }^{1,2}$ \\ Rifat Hanbali ${ }^{7}$ \\ Hashim Hashim ${ }^{8}$ \\ 'Department of Medicine, College of
} Medicine and Health Sciences, An-Najah National University, Nablus, 44839,

Palestine; ${ }^{2}$ Department of Urology, AnNajah National University Hospital, Nablus, 44839, Palestine; ${ }^{3}$ Division of Clinical Pharmacy, Hematology and Oncology Department, An-Najah National University Hospital, Nablus, 44839, Palestine; ${ }^{4}$ Department of Clinical and Community Pharmacy, College of Medicine and Health Sciences, An-Najah National University, Nablus, 44839, Palestine; ${ }^{5}$ Clinical Research Center, AnNajah National University Hospital, Nablus, 44839, Palestine; ${ }^{6}$ Poison Control and Drug Information Center (PCDIC), College of Medicine and Health Sciences, An-Najah National University, Nablus, 44839, Palestine; ${ }^{7}$ Department of Rheumatology, An-Najah National University Hospital, Nablus, 44839, Palestine; ${ }^{8}$ Bristol Urological Institute, North Bristol NHS Trust, Bristol, UK

Correspondence: Faris Abushamma Department of Medicine, College of Medicine and Health Sciences, An-Najah National University, Nablus, 44839, Palestine

Email farisabushamma@hotmail.com
Purpose: To assess the presence of lower urinary tract symptoms (LUTS) in rheumatoid arthritis (RA) female patients with assessment of LUTS and its impact on quality of life (QoL).

Patients and Methods: A prospective, cross-sectional study of female patients with RA was conducted. Demographics and clinical data, Bristol Female Lower Urinary Tract Symptoms questionnaire (BFLUTS), and the RA Disease Activity Score 28 (DAS28) were all collected. A correlation has been made between all variables to assess the factors that induce LUTS in RA and the impact on QoL.

Results: Eighty-nine patients were enrolled. About $94.4 \%$ of RA patients had at least one symptom of LUTS. Concerning DAS28, 55.1\% had moderate disease activity and $16.9 \%$ had high disease activity, which was not significantly associated with BFLUTS or QoL. The prevalence of overactive bladder syndrome symptoms (OAB: frequency, urgency, nocturia, and urgency incontinence) were found to be $65.2 \%, 59.6 \%, 56.2 \%$, and $30.3 \%$, respectively. Stress incontinence was prevalent in $40.4 \%$ of patients. The overall interference with life was evident in $27(30.3 \%)$ patients secondary to LUTS. Body mass index (BMI) was positively and significantly correlated with the presence of storage symptoms $(\mathrm{r}=0.306, p=0.004)$ and with the total BFLUTS $(\mathrm{r}=0.251, p=0.018)$. BFLUTS subdomains and total scores were significantly correlated to poor QoL. The correlation of the BFLUTS QoL was found to be $\mathrm{r}=0.584, p<0.001$ with storage symptoms, $\mathrm{r}=0.399, p<0.001$ with voiding symptoms, and $\mathrm{r}=0.757, p<0.001$ with incontinence.

Conclusion: LUTS is a prominent and significant disability that directly affects QoL in RA. BMI is an independent factor that is linked to LUTS in RA patients.

Keywords: lower urinary tract symptoms, rheumatoid arthritis, quality of life, DAS28, BFLUTS, overactive bladder

\section{Introduction}

Rheumatoid arthritis (RA) is a common type of inflammatory arthritis in women. ${ }^{1}$ It is an autoimmune disease that may present with extra-articular manifestations, such as pulmonary complications and Sjögren's syndrome. ${ }^{2}$ Rarely, RA may affect the urinary tract and has different clinical presentations, such as urinary tract infections (UTI), urolithiasis, and even de-novo lower urinary tract symptoms (LUTS). ${ }^{3}$ The combination of joint pain, stiffness, and other potential systematic involvement may directly negatively impact the quality of life (QoL) of such patients. ${ }^{4}$ LUTS is a broad category of symptoms that include storage, voiding, and post-micturition 
symptoms. ${ }^{5}$ It commonly affects women and causes significant distress. ${ }^{6}$ LUTS in females is either pathological or non-pathological, albeit both affect QoL negatively. For instance, the pregnant female can predominantly have nonpathological LUTS, especially towards the third trimester, and it affects QoL causing prominent stress and embarrassment. ${ }^{7,8}$ On the other hand, diabetic and spinal cord injury patients may present with LUTS secondary to a pathological insult to the urinary tract, such as UTIs and urolithiasis. ${ }^{9,10}$

The correlation between RA and LUTS is not well established, which creates a challenge to clinicians as both entities directly negatively impact the patient's QoL. ${ }^{11}$ Also, the factors that create or exacerbate LUTS in RA are still debatable and not yet discovered. Few published articles have studied the frequency of LUTS among patients with seropositive systemic inflammatory disease, which showed a high prevalence of voiding dysfunction among such a cohort. ${ }^{12-14}$ Furthermore, it is unclear whether RA directly causes LUTS or is part of the natural history of LUTS. Moreover, several factors need to be investigated in RA with LUTS, such as smoking, body mass index (BMI), and coffee intake, as these factors are correlated with the presence and severity of LUTS. ${ }^{15,16}$ RA disease activity is another valid question as it is unclear if disease status directly affects the presence and severity of LUTS among RA patients.

In this study, we recruited female patients with RA to evaluate the presence of lower urinary tract dysfunction in them. LUTS (storage, voiding, and incontinence), sexual function and their impact on QoL were explored in detail using the BFLUTS questionnaire. RA disease activity has also been studied in addition to different independent variables to describe the factors that may be related to LUTS in RA patients.

\section{Methods}

\section{Study Design}

This is a prospective and cross-sectional study that recruited adult female patients who have been diagnosed with RA.

\section{Study Setting}

This study was held at four different primary care clinics with rheumatology services, covering a population of 1.5 million, between December 2020 and April 2021.

\section{Inclusion and Exclusion Criteria}

Females diagnosed with RA and aged more than 18 years old were included. Patients with previous urological problems, previous urinary tract surgery, or recent documented or symptomatic UTIS were all excluded. Figure 1 shows consort diagram for including RA patients.

\section{Study Population and Sampling}

In this study, we included all female patients who had been diagnosed with RA. We performed a questionnaire survey using a judgmental sampling method to reach the patients. Based on the expected population during the research period and a $50 \%$ response distribution, the needed sample size was about 90 with a confidence level of $95 \%$ and a margin of error of $5 \%$.

\section{Data Collection}

The first set was the demographics and clinical data including age, BMI, the presence of DM, smoking, coffee intake, and duration of RA disease, which later was divided into four main categories: $\leq 1$ year, $>1-5$ years, $>5-10$ years, and more than ten years.

The second part included a self-administered Bristol Female Lower Urinary Tract Symptoms (BFLUTS) questionnaire. BFLUTS is an instrument created by Jackson et al in 1996 and used to assess a wide range of urinary symptoms. ${ }^{17,18}$ It consists of nineteen questions, which are divided into 5 domains as follows: four questions for filling domain (score range 0-15), three for voiding (score range 0-12), five for incontinence (score range 0 20 ), and the remaining seven questions are distributed with two questions to assess sexual function (score range 0-6) and five for quality of life (score range $0-18$ ). The respondents have to answer each question with a score from "0" to " 3 " or " 0 " to " 4 ", which indicates the frequency or severity of the symptoms. The resulting total score ranges between 0 and 71 . Higher scores represent more severe symptoms.

In the last part, the RA disease was assessed by applying Rheumatologic Disease Activity Score 28 (DAS28), which is a continuous measure of RA disease activity that combines information from swollen joints, tender joints, and acute-phase response. Accordingly, the output is categorized into four main groups, those who are in remission, where the DAS28 score is $\leq 2.6$, low disease activity when DAS28 between 2.6 and $\leq 3.2$, moderate disease activity with DAS28 score between 3.2 and $\leq 5.1$, and lastly, high 


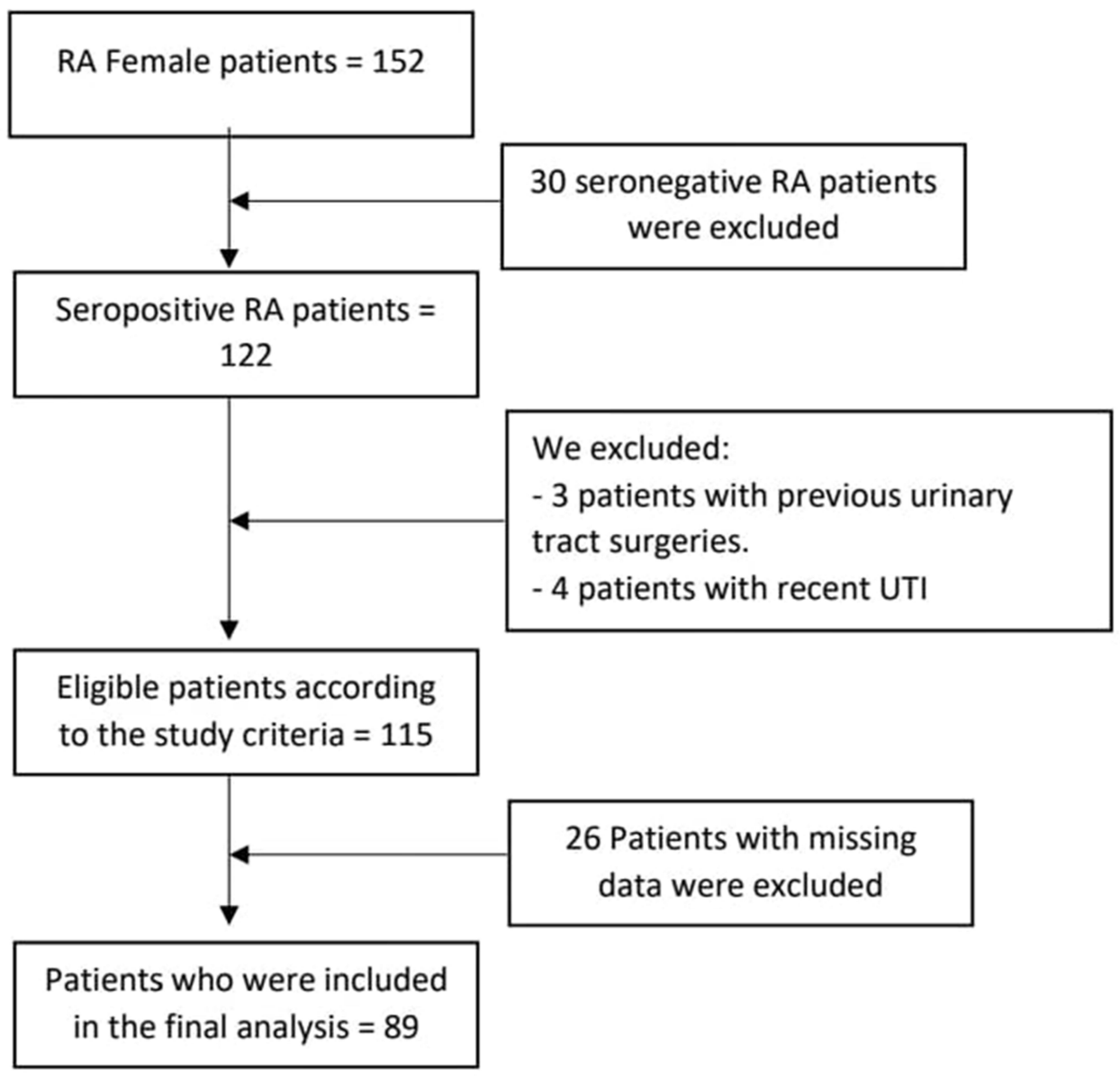

Figure I CONSORT diagram for including RA patients.

Notes: Adapted from: Schulz KF, Altman DG, Moher D, CONSORT Group. CONSORT 2010 Statement: Updated Guidelines for Reporting Parallel Group Randomised Trials. PLoS Med. 2010;7(3):el000251. ${ }^{34}$ Copyright: @ 2010 Schulz et al. Creative Commons Attribution License.

disease activity with DAS28 score above 5.1. The primary outcome was RA disease activity, and the secondary outcomes were LUTS and QoL.

\section{Statistical Analysis}

Data were entered and analysed using the Statistical Package for Social Sciences program (SPSS) version 21. Data were expressed as means $\pm \mathrm{SD}$ and median [Q1-Q3] for continuous variables, and as frequencies and percentages for categorical variables. We used the Pearson test to assess the correlations between BFLUTS, demographics and QoL. Kruskal Wallis and Mann Whitney $U$-test was used to analyse the patients' characteristics according to BFLUTS total score and sub-scores. The significance level was set at a p-value $<0.05$.

\section{Ethical Approval and Confidentiality}

All aspects of the study protocol, including access to and using patient clinical information, were authorized by An-
Najah National University Institutional Review Board (IRB), Nablus, Palestine. Before administering the survey or conducting interviews, each participant provided verbal informed consent. The IRB accepted the study protocol, including the verbal consent process, and there was no need for written consent. All participants were notified that their information will be coded and anonymized. The study was conducted according to the Declaration of Helsinki.

\section{Results}

\section{Patients' Demographics and Clinical Presentation}

Eighty-nine patients met the inclusion criteria. Patients' demographics and clinical presentation were collected. Majority of women were over 40 years old, and the majority had BMI over 30 . Around half of the patients have been diagnosed with RA within one year. Using 
DAS28, $13(14.6 \%)$ of the patients were in remission, 12 (13.5\%) had low disease activity, 49 (55.1\%) had moderate disease activity, and $15(16.9 \%)$ had high disease activity. Table 1 shows the patients' demographics and clinical presentation.

\section{Self-Administered BFLUTS}

We found that $94.4 \%$ of RA patients had at least one symptom of LUTS according to the BFLUTS

Table I Characteristics of the Participants $(N=89)$

\begin{tabular}{|l|c|}
\hline Variable & Frequency (\%) \\
\hline Age & $19(21.3)$ \\
$\geq 40$ & $70(78.7)$ \\
\hline Body mass index & \\
Normal (20-24.9) & $20(22.5)$ \\
Overweight (25-29.9) & $30(33.7)$ \\
Obese (30-34.9) & $39(43.8)$ \\
\hline Disease duration (years) & \\
$\leq 1$ & $41(46.1)$ \\
$>$ I-5 & $27(30.3)$ \\
$>5-10$ & $10(11.2)$ \\
$>$ I0 & $11(12.4)$ \\
\hline Diabetes mellitus type 2 & $11(12.4)$ \\
Yes & $78(87.6)$ \\
No & \\
\hline Smoking & $81(9.0)$ \\
Yes & $13(18.0)$ \\
No & $12(13.5)$ \\
\hline Daily Coffee intake & $49(55.1)$ \\
Yes & $15(16.9)$ \\
No & \\
\hline Rheumatoid Arthritis Disease activity & \\
Remission & \\
Low & \\
Moderate & \\
High & \\
\hline
\end{tabular}

questionnaire. The mean total BFLUTS score was 10.75 \pm 10.38 (range $0-43$ ). The mean score of filling symptoms was $4.82 \pm 3.19$ (range: $0-13$ ). The mean score of voiding symptoms was $0.61 \pm 1.35$ (range $0-8$ ). The mean score of incontinence was $2.31 \pm 3.50$ (range $0-16$ ). The mean score of QoL among the cohort was $3.01 \pm 4.57$ (range 0-16). Table 2 shows the BFLUTS score in each domain.

\section{BFLUTS Subdomains}

Table 3 shows the frequency of each symptom in the BFLUTS subdomain. The most prevalent symptoms are those of the overactive bladder syndrome.

\section{Storage Domain}

The storage symptoms were found to be as following: nocturia ( $>1$ times): 50 (56.2\%), urgency: 53 (59.6\%), and frequency: $58(65.2 \%)$.

\section{Voiding Domain}

The voiding symptoms were documented as following: hesitancy: 8 (9\%), straining: $8(9 \%)$, and intermittency: $14(15.7 \%)$

\section{Incontinence Domain}

Urinary incontinence is highly prevalent in our cohort with urgency incontinence found in 27 (30.3\%) patients, and stress incontinence found in $36(40.4 \%)$ patients.

\section{QoL Domain}

The overall interference with life was evident in $27(30 \%)$ patients secondary to LUTS.

\section{Correlation Between BFLUTS} Subdomains and Patients' Demographics BMI is positively and significantly correlated to the presence of storage symptoms $(\mathrm{r}=0.306, p=0.004)$ and to the total BFLUTS score $(r=0.251, p=0.018)$. Age is not correlated with the BFLUTS total score or subdomains.

Table 2 BFLUTS Scores of the Participants $(\mathrm{N}=89)$

\begin{tabular}{|l|l|l|l|}
\hline Domain & BFLUTS Range & BFLUTS Mean \pm SD & BFLUTS Median [QI-Q3] \\
\hline Filling & $0.0-13.0$ & $4.82 \pm 3.19$ & $5.0[2.0-7.0]$ \\
Voiding & $0.0-8.0$ & $0.61 \pm 1.35$ & $0.0[0.0-0.5]$ \\
Incontinence & $0.0-16.0$ & $2.31 \pm 3.50$ & $1.0[0.0-3.5]$ \\
Quality of life & $0.0-16.0$ & $3.01 \pm 4.57$ & $1.0[0.0-4.0]$ \\
Total BFLUTS & $0.0-43.0$ & $10.75 \pm 10.38$ & $7.0[3.0-14.0]$ \\
\hline
\end{tabular}


Table 3 Frequencies of Each BFLUTS Symptom for Each Domain $(\mathrm{N}=89)$

\begin{tabular}{|l|c|}
\hline Symptoms & $\begin{array}{c}\text { Frequency } \\
\text { (\%) }\end{array}$ \\
\hline Storage & $50(56.2)$ \\
Nocturia (> I time) & $53(59.6)$ \\
Urgency & $17(19.1)$ \\
Bladder pain & $58(65.2)$ \\
\hline Frequency & \\
\hline Voiding & $8(9.0)$ \\
Hesitancy & $8(9.0)$ \\
Strain to urinate & $14(15.7)$ \\
Intermittency (stop and start more than once) & \\
\hline Incontinence & $27(30.3)$ \\
Leaking before getting to the toilet (urge & $29(32.6)$ \\
incontinence) & $36(40.4)$ \\
Frequency of incontinence & $14(15.7)$ \\
Stress incontinence (when physically active, cough, & $3(3.4)$ \\
etc.) & $28(31.5)$ \\
Unpredictable incontinence (no reason and feeling) & $25(28.1)$ \\
Nocturnal incontinence (leaking when asleep) & $23(25.8)$ \\
\hline Sexual function & $25(28.1)$ \\
Sex life spoiled by urinary symptoms & $27(30.3)$ \\
Leaking during intercourse & $0(0.0)$ \\
\hline Quality of life & \\
Change outer clothing & \\
Cut down fluid & \\
Affect daily tasks & \\
Avoid situations where no toilet & \\
Overall interference with life & \\
\hline
\end{tabular}

BFLUTS subdomains and total score are significantly correlated with poor QoL. The correlation between the BFLUTS QoL was found to be $\mathrm{r}=0.584, p<0.001$ with storage symptoms, $\mathrm{r}=0.399, p<0.001$ with voiding symptoms, and $\mathrm{r}=0.757, p<0.001$ with incontinence. Table 4 shows the correlations between BFLUTS, demographics, and QoL.

\section{Impact of RA on LUTS and QoL}

The disease activity of RA measured by DAS 28 was not found to be associated with any domains of LUTS (filling, voiding, and incontinence), OoL, or total BFLUTS score. For example, the median (Q1-Q3) BFLUTS filling score for patients in remission was $4.0(2.0-4.5)$, while 5.5 (3.3-7.8) was for patients with low disease activity, 5.0 (2.5-7.5) was for the moderate activity category, and 4.0 (1.0-5.0) was for high disease activity, with an insignificant $p$-value (0.275). Another important RA-related parameter was the duration of disease, which also was not significantly associated with any domains of BFLUTS or QoL. As an example, the median [Q1-Q3] scores of the BFLUTS incontinence score were as follows: 1.0 [0.0-3.5] for disease duration of $\leq 1$ year, 0.0 [0.0-2.0] for $>1-5$ years, 3.5 [1.5-6.3] for $>5-10$ years, and 0.0 [0.0-5.0] for $>10$ years, with an insignificant $p$ value (0.091). Figure 2 shows the distribution of LUTS subdomains among DAS 28 categories. Table 5 shows the clinical variables and BFLUTS subdomain correlation.

\section{Discussion}

This study shows that RA patients frequently complain of LUTS, which affects their QoL. A previously published article describes a wide range of urological diseases more prevalent in RA patients, such as UTIs, urolithiasis, and urine retention. ${ }^{3}$ However, this study focused on LUTS, which had no obvious underlying cause and led to a negative impact on the patient's QoL. The detailed LUTS analysis which we have done allows us to conclude that the majority of RA patients complain of LUTS, which

Table 4 Correlations Between BFLUTS, Demographics, and QoL

\begin{tabular}{|l|l|c|c|c|c|}
\hline & & $\begin{array}{c}\text { BFLUTS-FS } \\
\text { (Storage) }\end{array}$ & $\begin{array}{c}\text { BFLUTS-VS } \\
\text { (Voiding) }\end{array}$ & $\begin{array}{c}\text { BFLUTS-IS } \\
\text { (Incontinence) }\end{array}$ & $\begin{array}{c}\text { BFLUTS- } \\
\text { Total }\end{array}$ \\
\hline Age & Pearson Correlation & 0.062 & -0.071 & 0.187 & 0.08 \\
0.185 \\
& Sig. (2-tailed) & 0.566 & 0.508 & 0.167 & 0.082 \\
\hline BMI & Pearson Correlation & $0.306^{* *}$ & 0.073 & 0.117 & $0.251^{*}$ \\
& Sig. (2-tailed) & $\mathbf{0 . 0 0 4}$ & 0.497 & $0.757^{* *}$ & $0.927^{* *}$ \\
BFLUTS- & Pearson Correlation & $0.584^{* *}$ & $0.399 * *$ & $<0.001$ & $<0.001$ \\
\hline
\end{tabular}

Notes: **Correlation is significant at the 0.01 level (2-tailed). *Correlation is significant at the 0.05 level (2-tailed). Bold figures indicate a significant $p$ value $(<0.05)$. Abbreviations: FS, Filling symptoms; VS, Voiding symptoms; IS, Incontinence symptoms. 


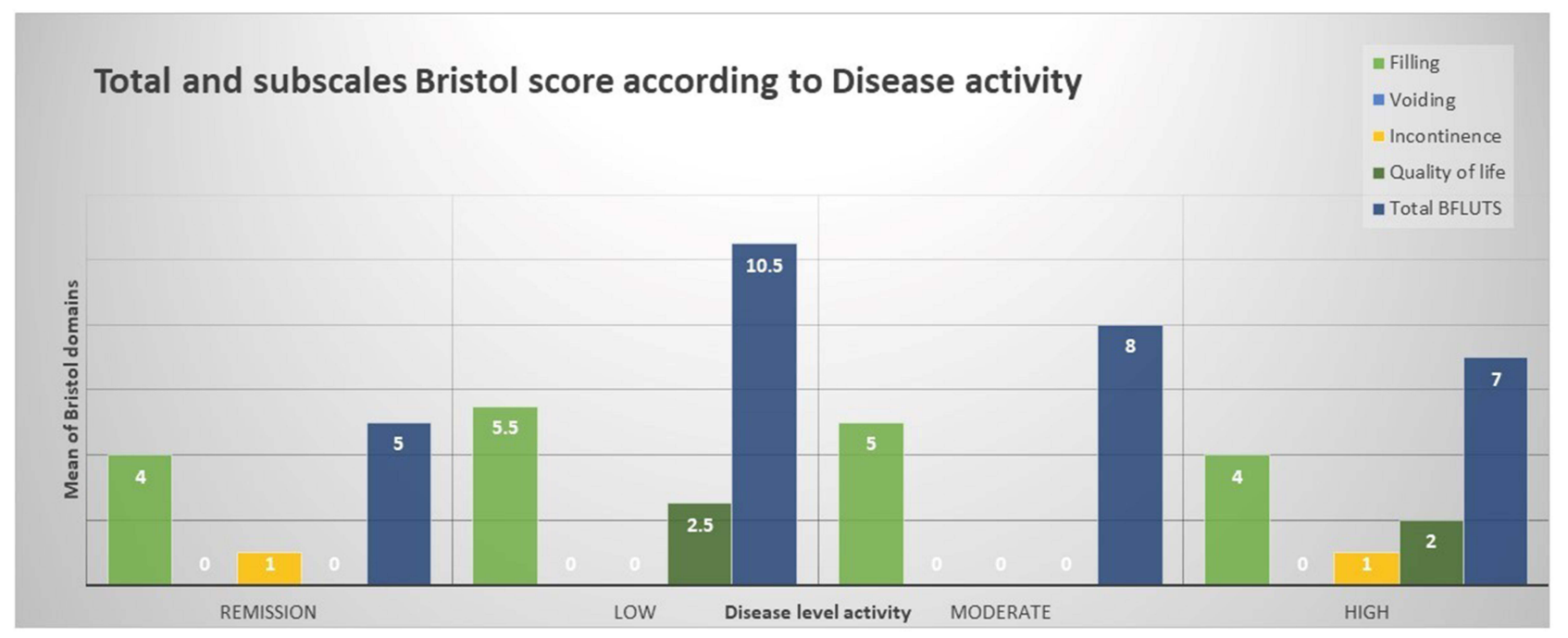

Figure 2 Subscales Bristol scores according to disease activity.

were overlooked by their treating physician and caused noticeable anxiety and interference with their daily activities.

The most prevalent group of symptoms were of overactive bladder syndrome $(\mathrm{OAB})$. The presence of $\mathrm{OAB}$ in seropositive systemic inflammatory disease was previously studied and showed significantly worse $\mathrm{OAB}$ in this group with a direct negative impact on QoL. ${ }^{19,20}$ Nocturia (56.2\%), urgency $(59.6 \%)$, and daytime frequency $(65.2 \%)$ were the most frequent symptoms in RA patients, according to our results, and these symptoms cause a direct negative impact on QoL $(p<0.001)$. The concept of the negative impact of $\mathrm{OAB}$ on QoL is well established in the literature in different cohorts of patients and the general population as well. ${ }^{7,21-23}$ The new finding in this study is that the detailed analysis of LUTS uncovered significant OAB in RA that patients and physicians usually overlook. Thus, a routine assessment of such symptoms is paramount for RA disease activity evaluation during RA follow-up clinics.

Furthermore, treatment of OAB should be offered to all symptomatic patients with idiopathic $\mathrm{OAB}$ to improve their QoL. The treatment entails primarily either behavioral treatment and/or medication, which can be offered at primary care centers. ${ }^{24,25}$ To conclude, a detailed assessment of LUTS and treatment counseling is essential for all RA patients and should be offered during follow-up.

Incontinence is another frequently encountered problem in this study. It was previously published that urinary incontinence is underreported in arthritis. ${ }^{26}$ However, in our study, stress incontinence (40.4\%) and urgency incontinence (30.3\%) are frequently seen in RA patients. This creates a new challenge as urinary incontinence had the highest correlation with QoL in this group. Thus, further studies are required to assess and analyze urinary incontinence to find factors that exacerbate such symptoms and establish treatment strategies. ${ }^{16,27}$

$\mathrm{BMI}$ is positively and significantly correlated to $\mathrm{OAB}$ symptoms and urinary incontinence in RA and is the main factor that may be responsible for LUTS in RA patients. $\mathrm{BMI}$ is well known as an independent variable to exacerbate $\mathrm{OAB}$ and urinary incontinence. ${ }^{28,29}$ Furthermore, weight reduction strategy is well known to improve LUTS and urinary incontinence. ${ }^{15}$ Thus, RA patients with LUTS have to be counseled regarding obesity, especially that obesity was previously linked to RA disease activity, poor response to treatment, and risk for long-term adverse outcomes.

Disease activity was not found to be correlated with LUTS. DAS 28 showed no significant difference between the four categories with respect to LUTS or LUTS-related poor QoL. Furthermore, DM is also not linked directly to LUTS in RA patients despite the available evidence to conclude that DM, in general, is linked to LUTS. ${ }^{30,31}$ Further analysis and studies are required to compare controlled DM and poorly controlled DM in view of LUTS, LUTS severity, and QoL.

Smoking and caffeine intake are not directly linked to LUTS in RA. However, smoking is weakly associated with improving LUTS. ${ }^{32}$ A recent review showed that the evidence is low regarding the impact of reduction 
Table 5 Patients' Characteristics According to Total BRISTOL Score and Subscores

\begin{tabular}{|c|c|c|c|c|c|c|}
\hline & $\mathbf{N}(\%)$ & $\begin{array}{c}\text { BFLUTS-FS } \\
\text { Median[QI-Q3] }\end{array}$ & $\begin{array}{c}\text { BFLUTS-VS } \\
\text { Median[QI-Q3] }\end{array}$ & $\begin{array}{c}\text { BFLUTS-IS } \\
\text { Median[QI-Q3] }\end{array}$ & $\begin{array}{c}\text { BFLUTS-QoL } \\
\text { Median[QI-Q3] }\end{array}$ & $\begin{array}{c}\text { BFLUTS-SF } \\
\text { Median[QI-Q3] }\end{array}$ \\
\hline \multicolumn{7}{|c|}{ Disease duration (yrs) } \\
\hline $\begin{array}{l}\leq 1 \\
>1-5 \\
>5-10 \\
>10\end{array}$ & $\begin{array}{l}4 I(46.1) \\
27(30.3) \\
10(11.2) \\
\text { II (I2.4) } \\
P \text {-value }\end{array}$ & $\begin{array}{c}5.0[3.0-7.0] \\
4.0[1.0-6.0] \\
4.5[2.8-8.5] \\
4.0[2.0-6.0] \\
0.602\end{array}$ & $\begin{array}{c}0.0[0.0-1.5] \\
0.0[0.0-0.0] \\
0.0[0.0-0.5] \\
0.0[0.0-0.0] \\
0.378\end{array}$ & $\begin{array}{c}1.0[0.0-3.5] \\
0.0[0.0-2.0] \\
3.5[1.5-6.3] \\
0.0[0.0-5.0] \\
0.091\end{array}$ & $\begin{array}{c}1.0[0.0-6.5] \\
0.0[0.0-2.0] \\
1.5[0.0-8.8] \\
0.0[0.0-1.0] \\
0.384\end{array}$ & $\begin{array}{c}9.0[3.0-19.0] \\
5.0[3.0-11.0] \\
11.5[5.0-19.0] \\
5.0[2.0-10.0] \\
0.193\end{array}$ \\
\hline \multicolumn{7}{|c|}{ Diabetes mellitus } \\
\hline $\begin{array}{l}\text { Yes } \\
\text { No }\end{array}$ & $\begin{array}{l}\text { II (12.4) } \\
78(87.6) \\
\text { P-value }\end{array}$ & $\begin{array}{c}6.0[1.0-8.0] \\
4.5[2.0-7.0] \\
0.764\end{array}$ & $\begin{array}{c}0.0[0.0-1.0] \\
0.0[0.0-0.3] \\
0.863\end{array}$ & $\begin{array}{c}0.0[0.0-1.0] \\
1.0[0.0-4.0] \\
0.187\end{array}$ & $\begin{array}{c}0.0[0.0-9.0] \\
1.0[0.0-4.0] \\
0.931\end{array}$ & $\begin{array}{c}7.0[1.0-21.0] \\
7.0[3.0-14.0] \\
0.896\end{array}$ \\
\hline \multicolumn{7}{|l|}{ Smoking } \\
\hline $\begin{array}{l}\text { Yes } \\
\text { No }\end{array}$ & $\begin{array}{c}8(9.0) \\
81(91.0) \\
\text { P-value }\end{array}$ & $\begin{array}{c}5.0[3.0-8.8] \\
4.0[2.0-7.0] \\
0.681\end{array}$ & $\begin{array}{c}0.0[0.0-1.8] \\
0.0[0.0-0.0] \\
0.477\end{array}$ & $\begin{array}{c}\text { I.0 }[0.0-4.0] \\
\text { I.0 }[0.0-3.0] \\
0.902\end{array}$ & $\begin{array}{c}0.5[0.0-7.5] \\
\mathrm{I} .0[0.0-4.0] \\
0.988\end{array}$ & $\begin{array}{c}8.5[4.3-20.0] \\
7.0[3.0-13.5] \\
0.575\end{array}$ \\
\hline \multicolumn{7}{|c|}{ Caffeine intake } \\
\hline $\begin{array}{l}\text { Yes } \\
\text { No }\end{array}$ & $\begin{array}{l}73(82.0) \\
16(18.0) \\
P \text {-value }\end{array}$ & $\begin{array}{c}5.0[2.5-7.0] \\
4.0[1.3-6.0] \\
0.516\end{array}$ & $\begin{array}{c}0.0[0.0-0.5] \\
0.0[0.0-0.8] \\
0.966\end{array}$ & $\begin{array}{c}0.0[0.0-3.5] \\
\mathrm{I} .5[0.0-3.8] \\
0.648\end{array}$ & $\begin{array}{c}1.0[0.0-5.0] \\
0.0[0.0-1.0] \\
0.132\end{array}$ & $\begin{array}{c}7.0[3.5-14.5] \\
7.0[2.3-12.8] \\
0.514\end{array}$ \\
\hline \multicolumn{7}{|c|}{ Disease activity } \\
\hline $\begin{array}{l}\text { Remission } \\
\text { Low } \\
\text { Moderate } \\
\text { High }\end{array}$ & $\begin{array}{l}13(14.6) \\
12(13.5) \\
49(55.1) \\
15(16.9) \\
P \text {-value }\end{array}$ & $\begin{array}{c}4.0(2.0-4.5) \\
5.5(3.3-7.8) \\
5.0(2.5-7.5) \\
4.0(1.0-5.0) \\
0.275\end{array}$ & $\begin{array}{c}0.0(0.0-0.0) \\
0.0(0.0-1.0) \\
0.0(0.0-0.5) \\
0.0(0.0-2.0) \\
0.746\end{array}$ & $\begin{array}{c}1.0(0.0-3.0) \\
0.0(0.0-3.8) \\
0.0(0.0-3.5) \\
1.0(0.0-4.0) \\
0.899\end{array}$ & $\begin{array}{c}0.0(0.0-1.0) \\
2.5(0.0-5.5) \\
0.0(0.0-5.5) \\
2.0(0.0-7.0) \\
0.168\end{array}$ & $\begin{array}{c}5.0(3.5-8.5) \\
10.5(4.8-14.8) \\
8.0(3.0-17.5) \\
7.0(3.0-15.0) \\
0.563\end{array}$ \\
\hline
\end{tabular}

caffeine on improving LUTS. However, urgency is improved with a decrease in coffee intake ${ }^{33}$ and fluid intake in general.

Surprisingly, we found that RA patients had no sexual symptoms. This may be due to social embarrassment that prevents patients from disclosing this information.

\section{Strengths and Limitations}

This is the first study to assess LUTS in RA using a detailed patient-reported outcome measure questionnaire. However, the absence of a control group (women with no RA) and the small sample size are the main limitations of this study. Small sample size of the subgroups made comparison analysis to be problematic. Certain variables, such as medication use and specifically RA medications, were not addressed in this study, which may have had an impact on developing LUTS. Furthermore, the impact on sexual function may have suffered reporting bias due to social embarrassment.

\section{Conclusions}

LUTS are a prominent and significant disability that directly affects QoL in RA. BMI is an independent risk factor that is linked to LUTS in RA patients. OAB and urinary incontinence are the main forms of LUTS in such a cohort of patients. Furthermore, amendable factors that may exacerbate LUTS among female patients with RA should be identified and targeted to improve such symptoms, directly impacting the patient's QoL.

\section{Acknowledgments}

Many thanks to the Clinical Research Centre of An-Najah National University Hospital for constant support and wise advice. The authors thank Prof Hashim Hashim from the 
Bristol Urological Institute, UK, for the English editing of the manuscript.

\section{Author Contributions}

All authors made substantial contributions to the conception and design, acquisition of data, or analysis and interpretation of data; took part in drafting the article or revising it critically for important intellectual content; agreed to submit to the current journal; gave final approval of the version to be published, and agreed to be accountable for all aspects of the work.

\section{Funding}

No specific grant was received from any public, commercial, or non-profit funding agency for this research.

\section{Disclosure}

Prof. Dr. Hashim Hashim reports personal fees from Medtronic, Astellas, Boston Scientific, and Allergan, outside the submitted work. The authors report no other potential conflicts of interest for this work.

\section{References}

1. van der Woude D, van der Helm-van Mil AHM. Update on the epidemiology, risk factors, and disease outcomes of rheumatoid arthritis. Best Pract Res Clin Rheumatol. 2018;32(2):174-187. doi:10.1016/j.berh.2018.10.005

2. Conforti A, Di Cola I, Pavlych V, et al. Beyond the joints, the extra-articular manifestations in rheumatoid arthritis. Autoimmun Rev. 2021;20(2):102735. doi:10.1016/j.autrev.2020.102735

3. Niazy M, Gaber W, Moghazy A, Salem HK. Urological comorbidities in Egyptian rheumatoid arthritis patients: risk factors and relation to disease activity and functional status. Egypt Rheumatol. 2017;39 (4):213-216. doi:10.1016/j.ejr.2017.04.006

4. Giacomelli R, Gorla R, Trotta F, et al. Quality of life and unmet needs in patients with inflammatory arthropathies: results from the multicentre, observational RAPSODIA study. Rheumatology (Oxford). 2015;54(5):792-797. doi:10.1093/rheumatology/keu398

5. Abrams P, Cardozo L, Fall M, et al. The standardisation of terminology of lower urinary tract function: report from the Standardisation Sub-committee of the International Continence Society. Neurourol Urodyn. 2002;21(2):167-178. doi:10.1002/nau.10052

6. Coyne KS, Sexton CC, Thompson CL, et al. The prevalence of lower urinary tract symptoms (LUTS) in the USA, the UK and Sweden: results from the Epidemiology of LUTS (EpiLUTS) study. BJU Int. 2009;104(3):352-360. doi:10.1111/j.1464-410X.2009.08427.x

7. Ahmad QT, Saffarini JH, Samara AM, et al. The impact of lower urinary tract symptoms on the quality of life during pregnancy: a cross-sectional study from Palestine. BMC Urol. 2020;20(1):191. doi:10.1186/s12894-020-00761-9

8. Saffarini JH, Ahmad QT, Samara AM, et al. Assessment of lower urinary tract symptoms during pregnancy: an observational cross-sectional study from Palestine. BMC Preg Childbirth. 2021;21 (1):84. doi:10.1186/s12884-021-03567-1

9. Wang CC, Kuo HC. Urothelial dysfunction and chronic inflammation in diabetic patients with overactive bladder. Low Urin Tract Symptoms. 2017;9(3):151-156. doi:10.1111/luts.12126
10. Haddad R, Denys P, Arlandis S, et al. Nocturia and nocturnal polyuria in neurological patients: from epidemiology to treatment. a systematic review of the literature. Eur Urol Focus. 2020;6 (5):922-934. doi:10.1016/j.euf.2020.02.007

11. Lee KL, Chen MY, Yeh JH, Huang SW, Tai HC, Yu HJ. Lower urinary tract symptoms in female patients with rheumatoid arthritis. Scand $J$ Rheumatol. 2006;35(2):96-101. doi:10.1080/ 03009740500395278

12. Yu HJ, Lee WC, Lee KL, Chen MY, Chen CY, Chen J. Voiding dysfunction in women with systemic lupus erythematosus. Arthritis Rheum. 2004;50(1):166-172. doi:10.1002/art.11431

13. Walker J, Gordon T, Lester S, et al. Increased severity of lower urinary tract symptoms and daytime somnolence in primary Sjogren's syndrome. J Rheumatol. 2003;30(11):2406-2412.

14. Haarala M, Alanen A, Hietarinta M, Kiilholma P. Lower urinary tract symptoms in patients with Sjogren's syndrome and systemic lupus erythematosus. Int Urogynecol J Pelvic Floor Dysfunct. 2000;11 (2):84-86. doi:10.1007/s001920050075

15. Subak LL, Wing R, West DS, et al. Weight loss to treat urinary incontinence in overweight and obese women. $N$ Engl $J$ Med. 2009;360(5):481-490. doi:10.1056/NEJMoa0806375

16. Danforth KN, Townsend MK, Lifford K, Curhan GC, Resnick NM, Grodstein F. Risk factors for urinary incontinence among middle-aged women. Am J Obstet Gynecol. 2006;194(2):339-345. doi:10.1016/j.ajog.2005.07.051

17. Jackson S, Donovan J, Brookes S, Eckford S, Swithinbank L, Abrams P. The Bristol female lower urinary tract symptoms questionnaire: development and psychometric testing. Br J Urol. 1996;77 (6):805-812. doi:10.1046/j.1464-410x.1996.00186.x

18. Brookes ST, Donovan JL, Wright M, Jackson S, Abrams P. A scored form of the Bristol Female Lower Urinary Tract Symptoms questionnaire: data from a randomized controlled trial of surgery for women with stress incontinence. Am J Obstet Gynecol. 2004;191 (1):73-82. doi:10.1016/j.ajog.2003.12.027

19. Pereira ESR, Romao VC, Neves M, et al. Overactive bladder symptom bother and health-related quality of life in patients with systemic lupus erythematosus and primary Sjogren syndrome. Lupus. 2019;28 (1):27-33. doi:10.1177/0961203318811605

20. Lee CK, Tsai CP, Liao TL, et al. Overactive bladder and bladder pain syndrome/interstitial cystitis in primary Sjogren's syndrome patients: a nationwide population-based study. PLoS One. 2019;14(11): e0225455. doi:10.1371/journal.pone.0225455

21. Coyne KS, Sexton CC, Kopp ZS, Ebel-Bitoun C, Milsom I, Chapple C. The impact of overactive bladder on mental health, work productivity and health-related quality of life in the UK and Sweden: results from EpiLUTS. BJU Int. 2011;108(9):1459-1471. doi:10.1111/j.1464-410X.2010.10013.x

22. Milsom I, Kaplan SA, Coyne KS, Sexton CC, Kopp ZS. Effect of bothersome overactive bladder symptoms on health-related quality of life, anxiety, depression, and treatment seeking in the United States: results from EpiLUTS. Urology. 2012;80(1):90-96. doi:10.1016/j. urology.2012.04.004

23. Choi WS, Heo NJ, Lee YJ, Son H. Factors that influence lower urinary tract symptom (LUTS)-related quality of life (QoL) in a healthy population. World J Urol. 2017;35(11):1783-1789. doi:10.1007/s00345-017-2052-2

24. Shamliyan T, Wyman J, Kane RL. AHRQ Comparative Effectiveness Reviews. Nonsurgical Treatments for Urinary Incontinence in Adult Women: Diagnosis and Comparative Effectivenes. Rockville (MD): Agency for Healthcare Research and Quality (US); 2012.

25. Herbison P, McKenzie JE. Which anticholinergic is best for people with overactive bladders? A network meta-analysis. Neurourol Urodyn. 2019;38(2):525-534. doi:10.1002/nau.23893

26. Turner-Stokes L, Frank AO. Urinary incontinence among patients with arthritis-a neglected disability. $J \quad R$ Soc Med. 1992;85 (7):389-393. 
27. Hsieh CH, Lee MS, Lee MC, Kuo TC, Hsu CS, Chang ST. Risk factors for urinary incontinence in Taiwanese women aged 20-59 years. Taiwan J Obstet Gynecol. 2008;47(2):197-202. doi:10.1016/ S1028-4559(08)60080-7

28. Al-Shaiji TF, Radomski SB. Relationship between body mass index and overactive bladder in women and correlations with urodynamic evaluation. Int Neurourol J. 2012;16(3):126-131. doi:10.5213/ inj.2012.16.3.126

29. Palma T, Raimondi M, Souto S, Fozzatti C, Palma P, Riccetto C. Correlation between body mass index and overactive bladder symptoms in pre-menopausal women. Rev Assoc Med Bras. 2014;60 (2):111-117. doi:10.1590/1806-9282.60.02.007

30. Papaefstathiou E, Moysidis K, Sarafis P, Ioannidis E, Hatzimouratidis K. The impact of Diabetes Mellitus on Lower urinary tract symptoms (LUTS) in both male and female patients. Diabetes Metab Syndr. 2019;13(1):454-457. doi:10.1016/j. dsx.2018.11.009
31. Tam CA, Helfand BT, Erickson BA. The relationship between diabetes, diabetes severity, diabetes biomarkers, and the presence of lower urinary tract symptoms: findings from the national health and nutrition examination survey. Urology. 2017;105:141-148. doi:10.1016/j.urology.2017.03.040

32. Hannestad YS, Rortveit G, Daltveit AK, Hunskaar S. Are smoking and other lifestyle factors associated with female urinary incontinence? The Norwegian EPINCONT Study. BJOG. 2003;110 (3):247-254. doi:10.1046/j.1471-0528.2003.02327.x

33. Le Berre M, Presse N, Morin M, et al. What do we really know about the role of caffeine on urinary tract symptoms? A scoping review on caffeine consumption and lower urinary tract symptoms in adults. Neurourol Urodyn. 2020;39(5):1217-1233. doi:10.1002/nau.24344

34. Schulz KF, Altman DG, Moher D, CONSORT Group. CONSORT 2010 Statement: Updated Guidelines for Reporting Parallel Group Randomised Trials. PLoS Med. 2010;7(3):e1000251.

\section{Publish your work in this journal}

The International Journal of General Medicine is an international, peer-reviewed open-access journal that focuses on general and internal medicine, pathogenesis, epidemiology, diagnosis, monitoring and treatment protocols. The journal is characterized by the rapid reporting of reviews, original research and clinical studies across all disease areas. The manuscript management system is completely online and includes a very quick and fair peer-review system, which is all easy to use. Visit http://www.dovepress.com/ testimonials.php to read real quotes from published authors. 